\title{
Study on the Layering of the Main Shaft of the Friction and Wear Testing Machine for Slip- per Pair Based on CFRP
}

\author{
Hu Lai ${ }^{1}$, Huaichao $\mathrm{Wu}^{2}$, Yeo Kiam Beng ${ }^{3}$, Ding Ning ${ }^{1}$, Siliang $\mathrm{Li}^{1}$ \\ ${ }^{1}$ Key Laboratory of Advanced Maufacturing Technology Ministry of Education,Guizhou University,Guizhou,Guiyang \\ 550025; E-mail:Laifinial@16.com, 1505011295@qq.com, lisiliangde@163.com \\ ${ }^{2}$ Mechanical Engineering College,Guizhou University, Guizhou,Guiyang 550025; E-mail: magoubs@sina.com \\ ${ }^{3}$ The Advanced Composites \& Materials, Faculty of Engineering, Universiti Malaysia Sabah, Malaysi; E-mail:noo- \\ ryeo@ums.edu.my
}

\begin{abstract}
Aiming to reveal the friction and wear performance of slipper pair, a high-precision slipper pair friction and wear testing machine must be used. Aiming at the material of the main shaft of the transmission system of MCMS-10 slipper pair friction and wear tester, a research on the main shaft material of the transmission system of the tester by CFRP (Carbon Fiber Reinforced Polymer) is presented. Mainly for the theoretical analysis of the mechanical properties of CFRP, establish a mathematical model, and use the ANSYS Workbench module to the transmission system modal and static analysis. Simultaneously, CFRP is applied to the test machine spindle whether it meets the test machine transmission system requirements, and the stratification of the spindle is compared and analyzed. The results show that the application of CFRP to the main shaft of MCMS-10 tester not only meets the requirement of experimental performance, but also improves its transmission performance on the basis of the original. The maximum displacement and the maximum stress of CFRP are reduced by $0.003513 \mathrm{~mm}$ and $13.576 \mathrm{MPa}$ respectively.
\end{abstract}

Keywords: Slipper Pair Friction and Wear Testing Machine, Spindle Stratification, CFRP; Mechanics, Static Analysis

\section{Introduction}

The research is mainly focused on the slipper pair, one of the three most important friction pairs in the high pressure axial piston pump with $35 \mathrm{MPa}$ and above in the aviation field of our country. In order to study the friction and wear performance of slipper pair and the bearing ability of lifting slipper pair due to accidental failure or dry friction state, a high-precision friction and wear test platform must be used to test [1]. However, in the test machine, the accuracy of the transmission system directly affects the test results of the slipper pair. Based on this requirement, it is proposed to use CFRP to change the spindle material in the transmission system to study whether the accuracy is up to the requirement, and even to improve the original traditional material. Carbon fibers not only possess the intrinsic properties of carbon materials, but also have excellent mechanical properties [1-2]. The specific gravity of carbon fibers is less than $1 / 4$ of that of steels. The tensile strength of carbon fibers is 7-9 times of that of steels. Young's modulus is three times that of traditional Glass Fiber (GF) and two times that of Kevlar Fiber (KF-49). In 1966, Watt et al. Of the Royal Institute of Aeronautics developed a new way to produce high-strength and high-modulus PAN-based carbon fibers [3-4]. In 1969, Toyota Company of Japan successfully studied the preparation of carbon fibers from polyacrylonitrile with special monomer copolymerization. And combined with carbonization technology of United Carbide Company of USA, high-strength and high-modulus carbon fibers were produced. In China, the development of carbon fiber began in the 1960s [5-6]. And the first PAN-based carbon fiber production line with a capacity of 2t/a was produced in 1976 [7].The research on high- strength carbon fiber was started in the $1980 \mathrm{~s}$, and the production capacity of $40 \mathrm{t} / \mathrm{a}$ pilot line was built in 1998 [8-9].

\section{Mechanical structure analysis of objects}

2.1 Analysis of energy conservation relation of objects

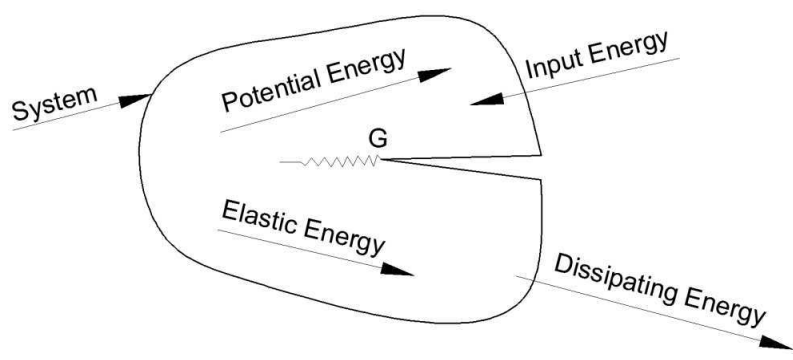

Fig. 1 Sketch of several energy parameters existing in physics

Where; $\delta U_{1}$-Input of energy; $\delta U_{2}$-Dissipating energy; $\delta U_{3}$-Elastic energy; $\delta U_{4}$-Potential energy. Thus, according to the principle of conservation of energy;

$$
\delta U_{1}-\delta U_{2}=\delta U_{3}+\delta U_{4}
$$

According to the elastic coefficient: $K=P E$, $F=K u$,

Where; $K=$ coefficient of elastic force; $E=$ modulus of elasticity; $F=$ total elastic force;

Therefor: 


$$
U_{3}=\int_{u_{1}}^{u_{2}} F \cdot d u=\frac{1}{2} P u
$$

When;

$$
U_{3}=U_{2}=0
$$

$$
\frac{\partial U_{1}}{\partial \mu}+\frac{\partial U_{1}}{\partial P} \cdot \frac{d P-d U}{d A}=\frac{3}{2} P
$$

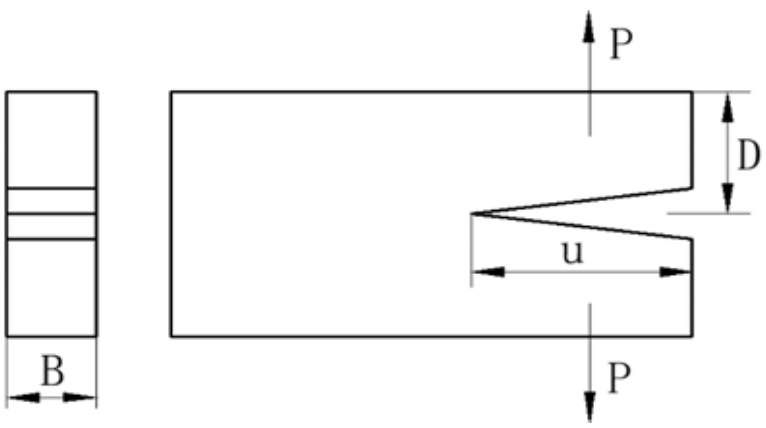

Fig. 2 A sketch of the force model of an object

$$
u=\frac{8 a^{3}}{E B D^{3}} P \quad C=\frac{u}{P}
$$

Simplify and finally get the total failure force of the body under the action of the tensile force $G$ :

$$
\begin{aligned}
& G=\frac{P}{6} \cdot \frac{1}{B^{2}(W-2 a) E}\left(P+\frac{\partial U_{1}}{\partial P} \cdot \frac{\frac{8 a^{3}}{E B D^{3}} P-1}{B^{2}(W-2 a) E}\right) \text { (3) } \quad \begin{array}{l}
\text { Therefore, the internal total } \\
\text { 3(A) is: }
\end{array} \\
& G=f_{1}(A)+f_{2}(A)=\frac{48}{E_{a} B^{2} H^{3}}\left(P_{1}^{2}+P_{2}^{2}-\left(P_{1}+P_{2}\right)^{2} \cdot \frac{1}{8}\right)
\end{aligned}
$$

\subsection{Theoretical study on stress of CFRP stratified fracture}

Not all fractures parallel to the fibrous lines are called stratified fractures. The fiber material itself also has cracks parallel to the direction of the fiber[10]. Damage caused by impact usually leads to this. Because impact can cause material stiffness to change. In the delamination study of carbon fiber composites, the rupture force in the delamination of carbon fiber composites should be obtained and expressed in terms of $G$.

And where in Fig. 3(A); $P_{1}=$ function $f_{1}(A) ; P_{2}=$ function $f_{2}(A)$;

So, the main forces in Fig. 3(A) of carbon fiber composites can be written: $G=f_{1}(A)+f_{2}(A)$

According to the previous section of Fig. 2, the forces on an object can be written separately:

$$
\begin{aligned}
& f_{1}(A)=\frac{6}{E_{a} B^{2} H^{3}}\left(P_{1}^{2}+P_{2}^{2}\right) \\
& f_{2}(A)=\frac{3}{4 E_{a} B^{2} H^{3}}\left(P_{1}+P_{2}\right)^{2} .
\end{aligned}
$$

Therefore, the internal total failure force $G$ in Fig.

For the opposite force in Fig. 3(B), then yield:

$$
G=\frac{96 P_{B}^{2}}{E_{a} B^{2} H^{3}}=\frac{96}{E_{a} B^{2} H^{3}}\left(\frac{P_{2}-P_{1}}{2}\right)^{2}
$$

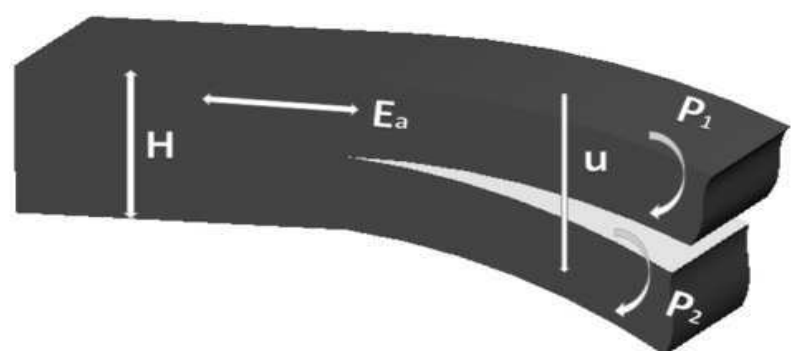

$\boldsymbol{A}$ Bending in the same direction

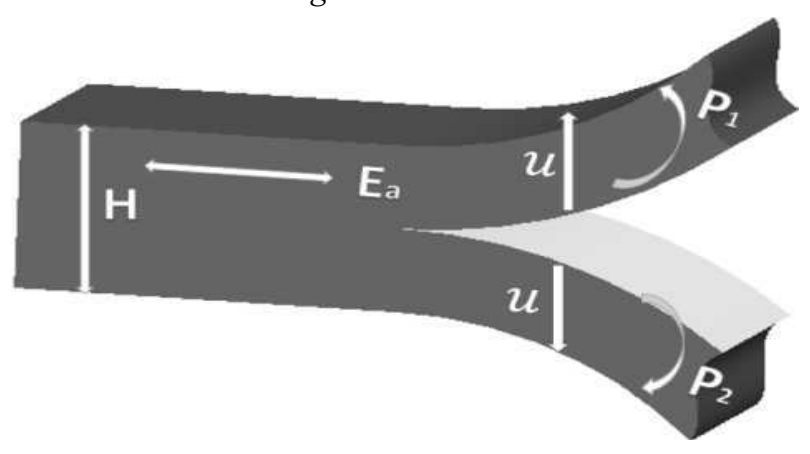

$\boldsymbol{B}$ Bending in different directions

Fig. 3 Stratified rupture by bending in different directions

\section{Research on Drive System of MCMS-10 Tes- ting Machine}

\subsection{Design of MCMS-10 Drive Structure}

The main shaft of the MCMS-10 slipper-wobble friction and wear tester is studied. The assembly diagram of the tester is shown in figure 4.

As shown in Fig. 4, the power is transferred from the synchronous belt 2 to the principal shaft 1 . The principal shaft 1 and the upper friction pair clamping device 5 transmit the torque to the upper friction pair 9 through a conical surface with a taper of 5 degrees, while the upper friction pair 9 and the lower friction pair 8 carry out friction and wear tests. Thus, the transmission system is composed of a spindle 1, an upper friction pair clamping device 5, a rotating bearing and other supporting components. The rotation accuracy and the reasonable degree of the structure of the main shaft 1 and the upper friction pair clamping device 5 will directly affect the testing accuracy of the testing machine. Therefore, according to figure 1 , the transmission system of its experimental platform is extracted, and its system is modeled by using Pro/E threedimensional software, as shown in figure 5. 


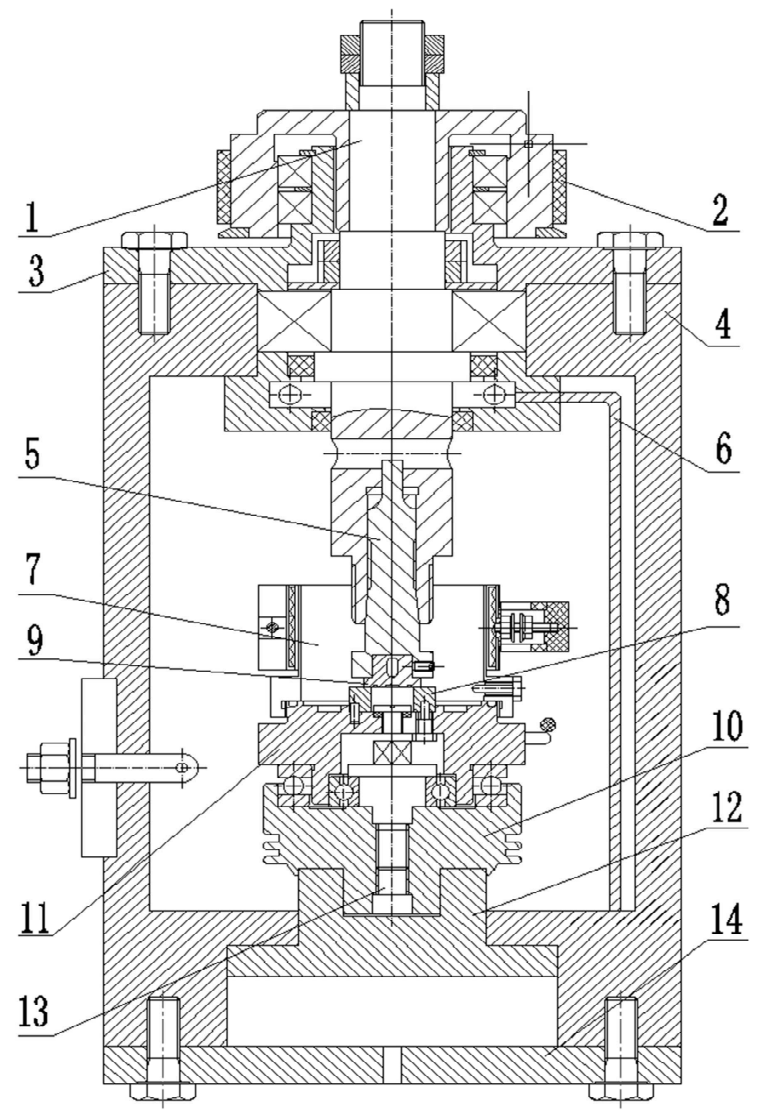

1. spindle; 2. synchronous belt; 3. top cover; 4. case; 5 . upper friction pair clamp; 6. spindle cooling oil route; 7. lubricating oil container; 8. down friction pair; 9. upper friction pair; 10. fixing support platforms; 11. rotating support platforms; 12. thrust pistons; 13. lifting axles; 14. bottom cap of case

Fig. 4 Two-dimensional assembly diagram of test platform

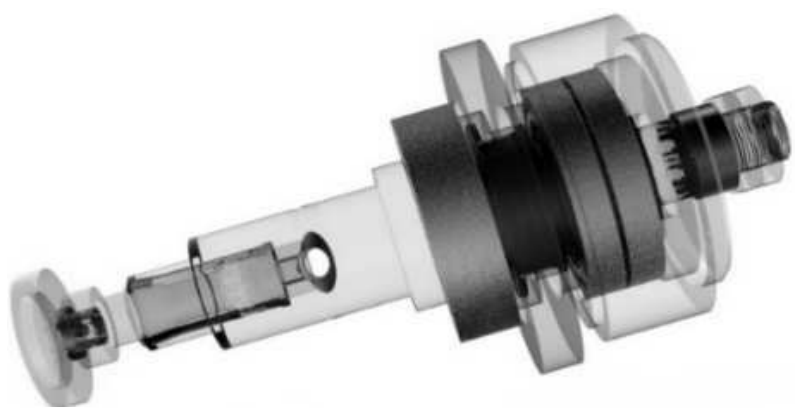

Fig. 5 Three-dimensional diagram of transmission system of testing machine

\subsection{Finite Element Analysis of MCMS-10 Drive Sys- tem}

Therefore, the Pro/E model shown in Figure 5 is imported into ANSYS [10-11]. Using ANSYS Workbench software for the whole traditional system and the main parts of the static characteristics and modal analysis, and the corresponding analysis results [12]. Before ANSYS analysis, the relevant parameters are set. According to the working principle of MCMS-10 slipper-disc friction and wear test platform, the boundary conditions are added and the simulated loads are applied. The torque $T=10.5 \mathrm{~N} . \mathrm{m}$ is calculated according to the power of the spindle motor and formula $T=\frac{9550 \cdot P \cdot \eta}{n}$. And the torque is applied to the spindle. The maximum friction force is $500 \mathrm{~N}$ and the maximum test force is $10 \mathrm{KN}$. After loading, the static characteristics of the transmission system are analyzed. The cloud figure of the displacement distribution is shown in Fig.6 and the cloud map of the stress distribution is shown in Fig.7. Simultaneously, in order to analyze the vibration frequency of the transmission system, the first three modes of the transmission system are extracted, as shown in Fig.8.

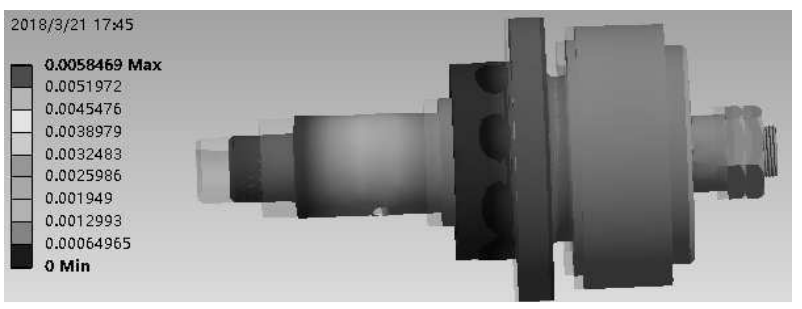

Fig.6 Displacement distribution nephogram

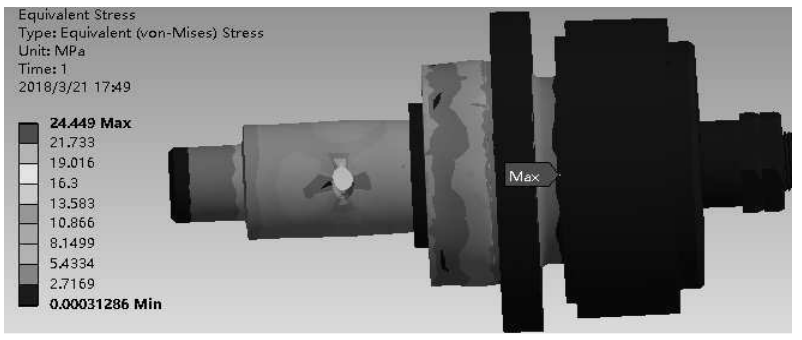

Fig.7 Stress distribution nephogram

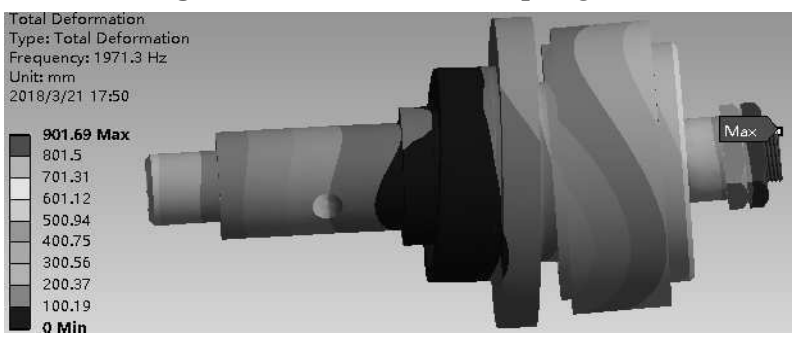

(a) First-order mode

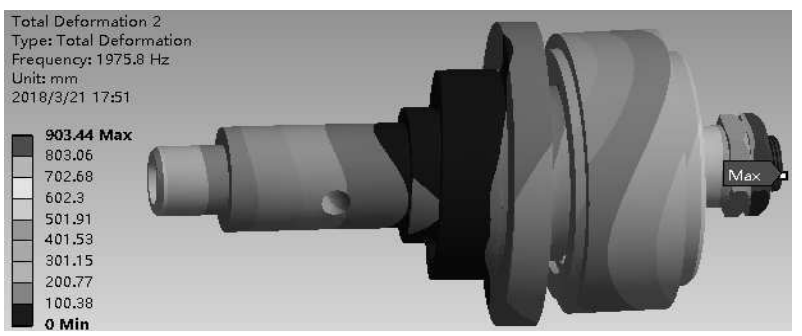

(b) Second-order mode

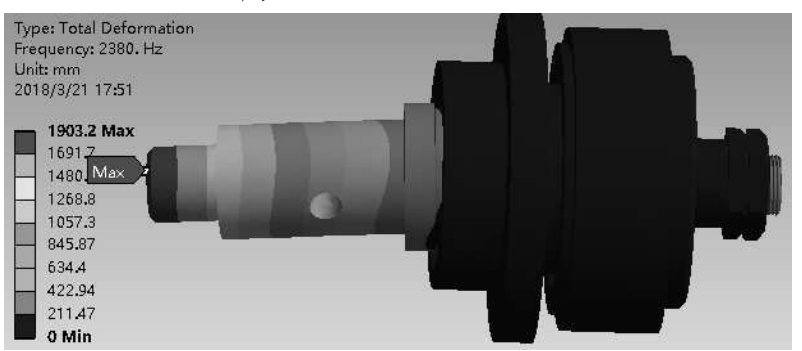

(c) Third-order mode

Fig. 8 First three - order modal deformation cloud maps of traditional system 
As shown in the cloud map of the displacement distribution of the transmission system in Fig.6, the maximum displacement occurs at the lower end of the spindle and the maximum displacement is $0.0058469 \mathrm{~mm}$. This is mainly due to the fact that the upper slipper pair is installed at the lower end of the spindle to test the displacement. As shown in the cloud map of the stress distribution of the traditional system in Fig.7. And the maximum stress occurs in the mounting part of the main shaft of the transmission system with a maximum stress value of 24.449 MPa. Because of the space control, the key steps for the analysis of the whole transmission system are given. The static characteristic parameters of the other main parts are shown in Tab.1 and the first three-order modal values are shown in Tab.2.

Tab. 1 Static Characteristic Parameters of Main Components of Transmission System

\begin{tabular}{|c|c|c|c|c|c|c|c|}
\hline Parameters & Unit & Spindle & Lower bearing & Upper bearing & Holding device & $\begin{array}{c}\text { Inner axle } \\
\text { ring }\end{array}$ & $\begin{array}{c}\text { Supporting } \\
\text { ring }\end{array}$ \\
\hline $\begin{array}{c}\text { Maximum } \\
\text { stress }\end{array}$ & $\mathrm{MPa}$ & 70.48 & 1.4633 & 3.0949 & 16.792 & 1.6031 & 1.3753 \\
\hline $\begin{array}{c}\text { Maximum dis- } \\
\text { placement }\end{array}$ & $\mathrm{mm}$ & 0.010595 & 3.671 & 3.5137 & 0.001883 & 3.8479 & 0.00012627 \\
\hline
\end{tabular}

Tab. 2 The first three-order modal parameters of the main components of the transmission system

\begin{tabular}{|c|c|c|c|c|c|c|c|}
\hline Parameters & Unit & Spindle & $\begin{array}{c}\text { Lower bea- } \\
\text { ring }\end{array}$ & Upper bearing & $\begin{array}{c}\text { Holding } \\
\text { device }\end{array}$ & $\begin{array}{c}\text { Inner axle } \\
\text { ring }\end{array}$ & $\begin{array}{c}\text { Supporting } \\
\text { ring }\end{array}$ \\
\hline First order & $\mathrm{Hz}$ & 243.52 & 50475 & $1.1201 \mathrm{e}+005$ & 2351.8 & 11864 & 11358 \\
\hline Second order & $\mathrm{Hz}$ & 243.53 & 50890 & $1.1207 \mathrm{e}+005$ & 2366.7 & 11912 & 11359 \\
\hline Third order & $\mathrm{Hz}$ & 373.14 & 51371 & $1.1212 \mathrm{e}+005$ & 10200 & 12151 & 11617 \\
\hline
\end{tabular}

As shown in Tab.1, the maximum stress occurs on the spindle of the test platform and the maximum stress is $70.48 \mathrm{MPa}$. Similarly, as shown in Tab.2, it is not difficult to see that the first three-order modal values of the spindle are much smaller than the modal values of components in other transmission systems. The first mode value is $243.53 \mathrm{MPa}$. In order to ensure the testing accuracy and running safety of the friction and wear tester, the maximum rotational speed of the spindle should not exceed $75 \%$ of the first order critical rotational number; meaning: $60 \times 243.5 \times 75 \%=10957.5 \mathrm{r} / \mathrm{min}$. The maximum rotational speed of the spindle of the MCMS-10 slipper-disc friction and wear tester is $5000 \mathrm{r} / \mathrm{min}$, which is far below the critical rotational number.

Similarly, according to the relationship between frequency and rotation: $n=60 f$, the maximum working frequency of the main shaft is $80.3 \mathrm{~Hz}$, and the natural frequency of the main shaft is $243.52 \mathrm{~Hz}$. Although this result is greater than the maximum operating frequency of the spindle, but the natural frequency of the spindle is relatively small, it is not far enough to meet the requirements, and can not be very good to avoid the resonance phenomenon. Therefore, the following consideration will be given to applying carbon fiber composites to the spindle of this friction and wear tester and to analyze whether it is improved or not.

\section{Layering of CFRP on MCMS-10 spindle}

\subsection{Manufacture process of CFRP layered test}

Before adding CFRP to the test machine spindle, firstly, the CFRP score layer is studied experimentally. Carbon fibers and bisphenol A epoxy resin were blended in proportion to form the cross section of carbon fiber composites, such as Fig.9. The yellow part was bisphenol A epoxy resin with a thickness of $0.62 \mathrm{~mm}$. The black part was carbon fiber with a thickness of $0.45 \mathrm{~mm}$.
The carbon fiber composites are then heated and solidified as shown in Fig.10. The temperature is 170 degrees and the heating time is 2 hours. Then the temperature is slowly cooled at room temperature. Then the lamination is homogeneous, as shown in Fig. 11.

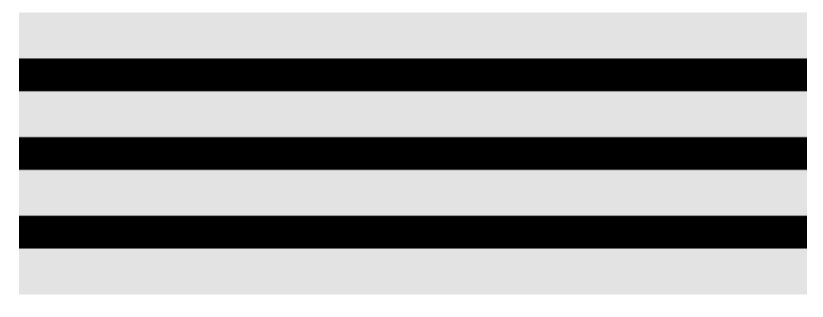

Fig.9 Cross-section profiling of carbon fiber composites

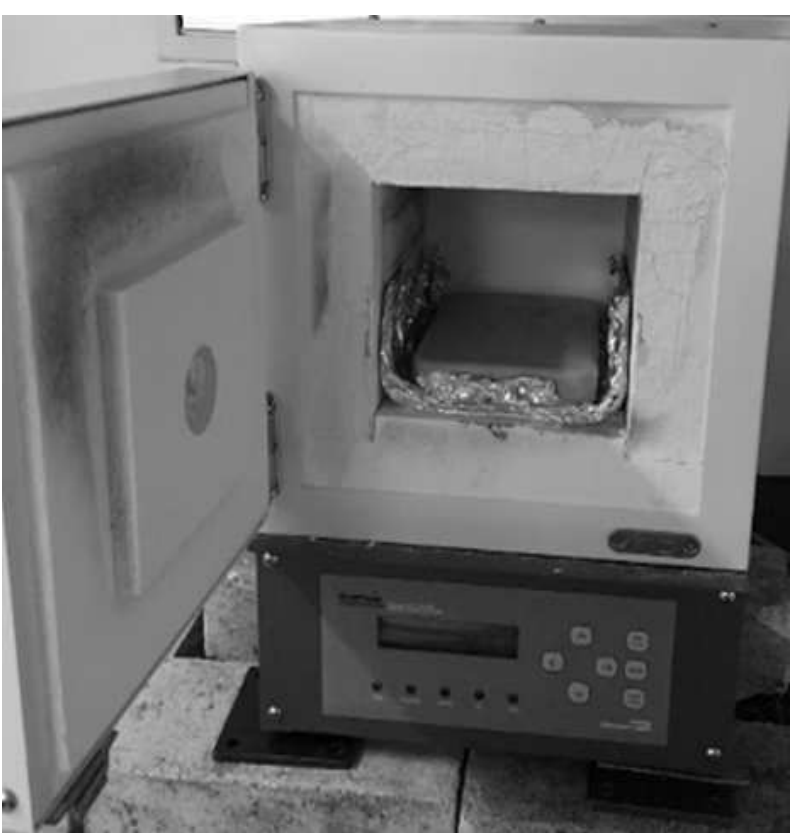

Fig.10 Heat solidification equipment for carbon 


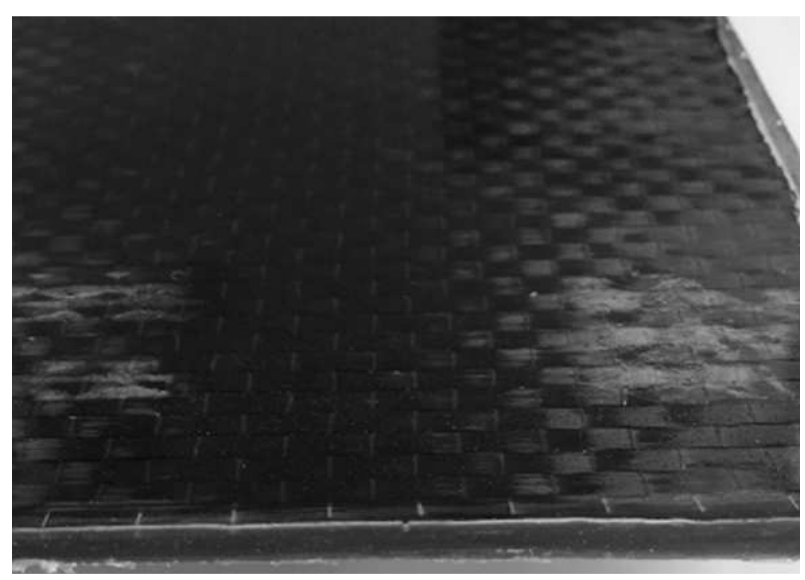

Fig.11 Sample completion of carbon fiber composites

\subsection{Static analysis of carbon fiber composites}

Combined with formulas (3) and (5), the sample was modeled and analyzed for its static characteristics and modes. The CFRP samples were modeled according to $1: 1$ and the parameters of CFRP samples were set. Subsequently, grids are mapped-applying loads and boundary conditions. The loads of $100 \mathrm{~N}, 500 \mathrm{~N}, 1000 \mathrm{~N}, 2000 \mathrm{~N}$,
$5000 \mathrm{~N}$ are analyzed according to the two kinds of loading methods, such as Fig. 4 (A) and (B). The results of the analysis are shown in Tab.3 and Tab.4.

From Tab.3: When the sample is subjected to the same bending force in the same direction, the value of displacement and stress increases with the increase of load. Aiming to study the actual vibration frequency, we can analyze the first-order modal value. The first mode is when the excitation frequency of the external force is equal to the natural frequency of the object. The first mode of the object is called the first mode or the main mode of the vibration. So the first-order modal value decreases with the increase of load, which indicates that the vibration frequency in the experiment can not meet the requirement when the load is more and more large.Similarly, as shown in Tab.4, the trends of displacement and stress values are the same as those in Tab.1. But in the first mode, when the load is increased from $500 \mathrm{~N}$ to $1000 \mathrm{~N}$, the modal value increases with the increment of $1.63 \mathrm{~Hz}$, which is acceptable. Therefore, in the light of Tab. 1 and 2, this delamination meets the requirements for static characteristics, and we also apply this delamination to the spindle of the friction and wear tester.

Tab. 3 Analysis results of CFRP samples bent in the same direction

\begin{tabular}{|c|c|c|c|c|c|c|c|c|}
\hline $\begin{array}{c}\text { Parame- } \\
\text { ters }\end{array}$ & $\begin{array}{c}\text { Displace- } \\
\text { ment } \\
(\mathrm{mm})\end{array}$ & $\begin{array}{c}\text { Stress } \\
(\mathrm{MPa})\end{array}$ & $\begin{array}{c}\text { First or- } \\
\text { der } \\
(\mathrm{Hz})\end{array}$ & $\begin{array}{c}\text { Second or- } \\
\text { der }(\mathrm{Hz})\end{array}$ & $\begin{array}{c}\text { Third or- } \\
\text { der }(\mathrm{Hz})\end{array}$ & $\begin{array}{c}\text { Fourth or- } \\
\text { der }(\mathrm{Hz})\end{array}$ & $\begin{array}{c}\text { Fifth or- } \\
\text { der }(\mathrm{Hz})\end{array}$ & $\begin{array}{c}\text { Sixth or- } \\
\text { der(Hz) }\end{array}$ \\
\hline $100 \mathrm{~N}$ & 0.045837 & 150.1 & 131.6 & 216.6 & 493.2 & 848.6 & 999.5 & 1138 \\
\hline $500 \mathrm{~N}$ & 0.22919 & 750.4 & 131.3 & 213.3 & 493.1 & 847.5 & 998.4 & 1137 \\
\hline $1000 \mathrm{~N}$ & 0.45837 & 1501 & 131.0 & 208.9 & 493.1 & 846.1 & 997.0 & 1137 \\
\hline $2000 \mathrm{~N}$ & 0.91675 & 3001 & 130.1 & 199.0 & 492.9 & 842.8 & 993.8 & 1136 \\
\hline $5000 \mathrm{~N}$ & 2.2919 & 7504 & 126.1 & 155.7 & 492.3 & 832.3 & 979.4 & 1114 \\
\hline
\end{tabular}

Tab. 4 Analysis of CFRP samples bent in opposite directions

Tab. 4 Analysis of CFRP samples bent in opposite directions
\begin{tabular}{|c|c|c|c|c|c|c|c|c|}
\hline $\begin{array}{c}\text { Parame- } \\
\text { ters }\end{array}$ & $\begin{array}{c}\text { Displace- } \\
\text { ment } \\
(\mathrm{mm})\end{array}$ & $\begin{array}{c}\text { Stress } \\
(\mathrm{MPa})\end{array}$ & $\begin{array}{c}\text { First order } \\
(\mathrm{Hz})\end{array}$ & $\begin{array}{c}\text { Second } \\
\text { order } \\
(\mathrm{Hz})\end{array}$ & $\begin{array}{c}\text { Third or- } \\
\text { der } \\
(\mathrm{Hz})\end{array}$ & $\begin{array}{c}\text { Fourth or- } \\
\text { der } \\
(\mathrm{Hz})\end{array}$ & $\begin{array}{c}\text { Fifth or- } \\
\text { der } \\
(\mathrm{Hz})\end{array}$ & $\begin{array}{c}\text { Sixth or- } \\
\text { der } \\
(\mathrm{Hz})\end{array}$ \\
\hline $100 \mathrm{~N}$ & 7.822 & 547.53 & 110.4 & 117.9 & 386.8 & 794.1 & 812.0 & 972.2 \\
\hline $500 \mathrm{~N}$ & 39.11 & 2737.7 & 109.5 & 113.8 & 374.9 & 791.7 & 809.6 & 971.5 \\
\hline $1000 \mathrm{~N}$ & 58.65 & 8569.7 & 111 & 363.6 & 707.4 & 806.6 & 958.0 & 1124.7 \\
\hline $2000 \mathrm{~N}$ & 117.3 & 17139 & 104 & 318.2 & 613.6 & 823.4 & 955.1 & 1094.7 \\
\hline $5000 \mathrm{~N}$ & 293.2 & 42849 & 65.81 & 234.1 & 375.7 & 804.9 & 921.7 & 1034.7 \\
\hline
\end{tabular}

\subsection{Stratified Analysis of CFRP on Main Axis}

The experimental results of CFRP can preliminarily judge that it meets the working requirements of the spindle in the transmission system of MCMS-10 tester. In order to verify whether the test machine is satisfied, the main parameters of the test machine are extracted separately, and the performance of the CFRP parameters are set up under the layered boundary conditions of loading and loading. The main parameters of the test machine include: material density 1.62 , Poisson's ratio 0.31 , shear strength $105 \mathrm{MPa}$, longitudinal tensile strength $1700 \mathrm{MPa}$, transverse tensile strength $81.3 \mathrm{MPa}$, longitudinal tensile modulus $120 \mathrm{GPa}$, transverse tensile modulus $8.8 \mathrm{GPa}$ and Young's modulus $245 \mathrm{GPa}$. Then the static characteristics of the spindle are analyzed. The CFRP spindle displacement nephogram is shown in Fig. 12 and the CFRP spindle stress nephogram is shown in Fig.13.
According to Fig. 12, the maximum displacement occurs when the lower end of the spindle is fitted with the upper friction pair clamping device, and the maximum displacement is $0.007082 \mathrm{~mm}$. The maximum displacement is in accordance with the requirements of MCMS10 tester, and the maximum displacement is far less than $0.010595 \mathrm{~mm}$ of the original material of the spindle. As shown in Fig.13, the maximum stress of CFRP spindle is $55.327 \mathrm{MPa}$, which occurs when the lower end of the spindle is fitted with the upper friction pairs. It can be seen that the maximum stress of the spindle is about $56.904 \mathrm{MPa}$ less than that of the original material of the spindle, $70.48 \mathrm{MPa}$ less than that of the original material of the spindle. Through the comparison of the two parameters, it can be explained that CFRP not only meets the requirements of the MCMS-10 test machine, but also improves the performance of the MCMS-10 test machine. 


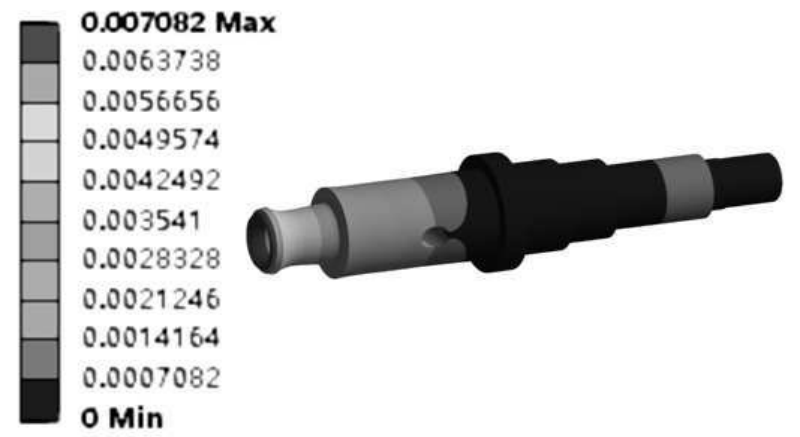

Fig. 12 Principal axis displacement cloud diagram of carbon fiber composites

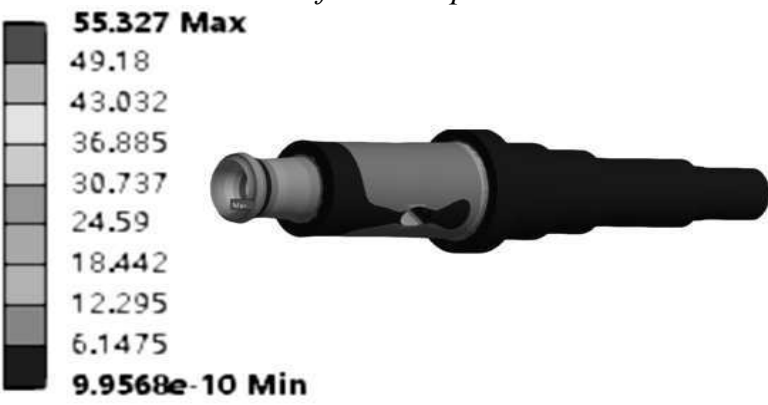

Fig. 13 Stress cloud diagram of carbon fiber composites

\section{Conclusion}

Through the derivation of the mathematical model of $G$ in material mechanics and the mechanical performance of CFRP, combined with the analysis of the transmission system of MCMS-10 testing machine. It is verified that CFRP not only meets the performance requirement of MCMS-10 test machine, but also improves its transmission performance on the original basis. The maximum displacement decreases by $0.003513 \mathrm{~mm}$ and the maximum stress decreases by $13.576 \mathrm{MPa}$. The proposed method is feasible at least on the MCMS-10 tester and also provides a theoretical and experimental basis for other similar studies.

\section{Acknowledgement}

This project is supported by training plan for high-level innovative talent in Guizhou Province (Grant No. Q.K.H.P.T.R.C【2016】 5659),preferred project of scientific and technological activities for personnel studying abroad in Guizhou Province(Grant No. Q.R.X.M.Z.Z.H.T(2018)0001),science and technology planning project in Guizhou Province (Grant No. Q.K.H.P.T.R.C[2017]5788) and key research project on Innovation group in Guizhou Provincial Education Department (Grant No. Q.J.H. KY Z. [2018]011).

\section{References}

[1] Fibre Carbon Fibres and Their Composites [J]. Fiber Reinforced Plastics/Composites, 2018 (02): 110-114.
[2] CHEN R R, WANG X W. (2010). Properties, Applications and Related Standards of Polyacrylonitrile (PAN) carbon fibers [J]. China Fiber Inspection 2010 (6): 75-79.

[3] WU, HUAICHAO, KUNPENG WANG, GUNCHAO SUN A LIMEI ZHAO. (2018). Influence study of oil film thrust bearing on thermal characteristics of high-speed precision roll grinding head. Manufacturing Technology. 18(2), 330-336. ISSN 1213-2489.

[4] LIU YANG, LI LI NAN, CHEN MING, et al. (2015). Comparison of Cutting Forces and Cutting Temperatures of Two Drills in High Speed Drilling Carbon Fiber Composite [J]. Materials for Mechanical Engineering, 2015, 39 (11): 3640.

[5] HA S K, KIM M H, HAN S C, et al. (2006). Design and Spin Test of A Hybrid Composite Flywheel Rotor with A Split Type Hub [J]. Journal of Composite Materials,2006,40(23):21132130.

[6] SEGL'A, Š. (2018). Kinematic analysis and optimization of a wheel loader mechanism. Manufacturing Technology.18(2), 309-314. ISSN 1213-2489.

[7] HIROSHIMA, N., HATTA. H,,KOYAMA, M.,et al. Optimization of Flywheel Rotor Made of Three-dimensional Composites[J].Composite Structures, 2015,131:304-311.

[8] HA, S. K.,YOON, Y, B.,HAN, S. C. (2000). Effects of Material Properties On The Total Stored Energy of A Hybrid Flywheel Rotor[J]. Archive of Applied Mechanics,2000,70(8-9): 571-584.

[9] BLATNICKÁ, M., BLATNICKÝ, M., DIŽO, J., SÁGA, M. (2018). Comparison of analytical stress analysis and numerical calculation of mobile work machine part. Manufacturing Technology. 18(2), 190-193. ISSN 1213-2489.

[10] WANG Yue-chang, LIU Ying, HUANG Weifeng, et al. (2017). ANSYS Interference Fit Analysis of Mechanical Seals in Reactor Coolant Pumps [J]. Journal of Mechanical Engineering, 2017, 53 (05): 153-159.

[11] LI HONGWEI, YU WENTAO, LIU SHUQIN. (2014). Mode Analysis and Design of Maglev Flexible Rotor with ANSYS [J]. China Mechanical Engineering, 2014, 25 (11): 1447-1452+1459.

[12] BARBERO E J. (2013). Finite Element Analysis of Composite Materials Using ANSYS,Second Edition [M]. CRC Press, 2013. 